\title{
A thermodynamic feasibility study of an Organic Rankine Cycle (ORC) for heavy-duty diesel engine waste heat recovery in off-highway applications
}

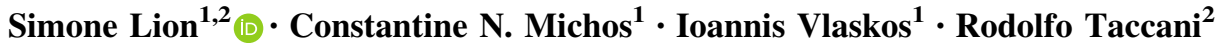

Received: 28 November 2016/ Accepted: 12 April 2017/Published online: 24 April 2017

(c) The Author(s) 2017. This article is an open access publication

\begin{abstract}
This work assesses the possibility of fitting an organic Rankine cycle (ORC) system in a commercial agricultural tractor, recovering waste heat from a $300-\mathrm{kW}$ brake power heavy-duty diesel engine. Two different cycle architectures are considered: a single evaporator layout to recover tail-pipe exhaust heat, and a parallel evaporator configuration to recover both exhaust and exhaust gas recirculation (EGR) heat. A second lower-temperature cooling circuit is also considered as possible different heat sink for the ORC system. Ten different working fluids have been assessed, and the optimum system configuration, in terms of fuel consumption, has been obtained applying an optimization algorithm to a process simulation model. A preliminary study has been carried out to evaluate the impact of the ORC system on the engine-vehicle-cooling system. A maximum fuel consumption reduction of $10.6 \%$ has been obtained using methanol and recovering heat from tail-pipe and EGR. However, considering also components and heat rejection performance, water steam, toluene and ethanol allow to obtain the best compromises between thermodynamic performance and engine-vehicle-cooling circuit impact.
\end{abstract}

Keywords Waste heat recovery - Organic rankine cycle . Heavy-duty diesel engine · Vehicle · Off-highway ·

Agricultural tractor

Simone Lion

simone.lion@ricardo.com; simone.lion@phd.units.it

1 Ricardo Deutschland GmbH, Güglingstraße 66, 73529 Schwäbisch Gmünd, Germany

2 University of Trieste, Piazzale Europa 1, 34128 Trieste, Italy

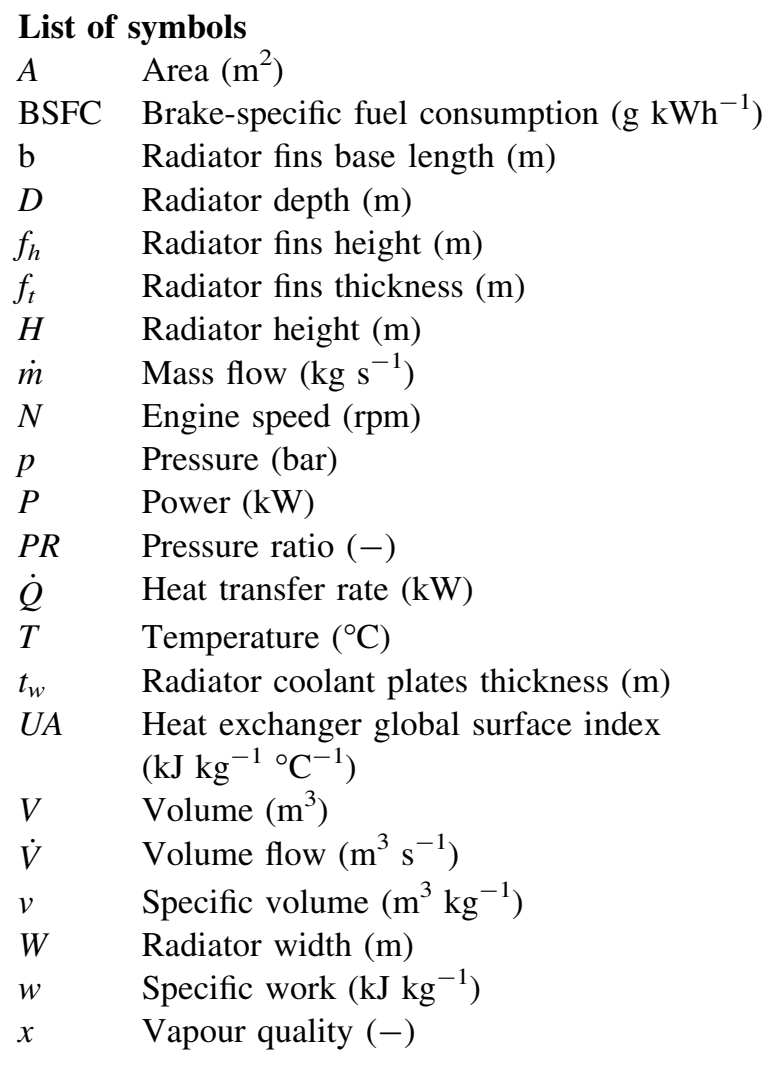

\section{Acronyms}

$\begin{array}{ll}\text { CAC } & \text { Charge air cooler } \\ \text { DOC } & \text { Diesel oxidation catalyst } \\ \text { DPF } & \text { Diesel particulate filter } \\ \text { EXP } & \text { Expander } \\ \text { EGR } & \text { Exhaust gas recirculation } \\ \text { EPA } & \text { Environmental Protection Agency (United } \\ & \text { States) } \\ \text { GA } & \text { Genetic algorithm }\end{array}$




$\begin{array}{ll}\text { GWP } & \text { Global warming potential } \\ \text { HDDE } & \text { Heavy-duty diesel engine } \\ \text { HPC } & \text { High-pressure compressor } \\ \text { HPT } & \text { High-pressure turbine } \\ \text { HT } & \text { High temperature (cooling circuit) } \\ \text { HX } & \text { Heat exchanger } \\ \text { IC1 } & \text { Indirect condensation 1 } \\ \text { IC2 } & \text { Indirect condensation 2 } \\ \text { LMTD } & \text { Log mean temperature difference } \\ \text { LPC } & \text { Low-pressure compressor } \\ \text { LPT } & \text { Low-pressure turbine } \\ \text { LT } & \text { Low temperature (cooling circuit) } \\ \text { NFPA } & \text { National Fire Protection Association } \\ \text { ORC } & \text { Organic Rankine cycle } \\ \text { P } & \text { Pump } \\ \text { PC } & \text { Parallel cycle } \\ \text { PTO } & \text { Power take-off } \\ \text { SC } & \text { Simple cycle } \\ \text { SCR } & \text { Selective catalytic reducer } \\ \text { WHR } & \text { Waste heat recovery }\end{array}$

\section{Greek letters}

$\eta \quad$ Efficiency (\%)

$\rho$ Density $\left(\mathrm{kg} \mathrm{m}^{-3}\right)$

$\tau$ Engine torque $(\mathrm{Nm})$

\begin{tabular}{ll}
\multicolumn{2}{l}{ Subscripts and superscripts } \\
abs & Absorbed \\
Air & Cooling air \\
Boil & Boiling (boiling point) \\
c & Critical (critical point) \\
cf & Cooling fluid \\
Cond & Condensation \\
de-superh & De-superheating \\
E & Expander \\
EGR & Exhaust Gas Recirculation \\
eng & Engine \\
eng + ORC & Combined engine-ORC \\
evap & Evaporation \\
exh & Exhaust gas \\
f & Frontal (area, radiator) \\
fan & Fan \\
freeze & Freezing (freezing point) \\
impr & Improvement (BSFC) \\
IN & Inlet \\
Incr & Radiator dimensions' increase \\
Is & Isentropic \\
Mech & Mechanical \\
Net & Net (power) \\
ORC & Organic Rankine Cycle \\
OUT & Outlet \\
P & Pump \\
PP & Pinch point \\
&
\end{tabular}

$\begin{array}{ll}\text { Rad } & \text { Radiator } \\ \text { sub-cool } & \text { Sub-cooling } \\ \text { sh } & \text { Super-heating } \\ \text { wf } & \text { Working fluid }\end{array}$

\section{Introduction}

In a common heavy-duty diesel engine (HDDE), around $40-45 \%$ of the fuel energy is converted to brake power and delivered to the crankshaft for propulsion or power generation use, while the remaining energy is lost due to friction, heat losses, heat transfer to the ambient, and the cooling system and unused exhaust gas. For all these reasons, engine waste heat recovery systems, such as organic Rankine cycles (ORC), are becoming very attractive, in order to improve fuel consumption and engine efficiency, with the purpose of meeting new restrictive emissions legislations.

Several studies are available in literature about implementation of ORCs in vehicles applications, and in particular to recover waste heat from HDDE for long-haul trucks, but fewer consider also the impact of fitting the bottoming cycle on the vehicle thermal management and on the engine cooling capabilities.

Some overviews of waste heat recovery studies and applications, for internal combustion engines using ORC, are reported by Sprouse and Depcik [1] and by Wang et al. [2].

One of the first implementations of an ORC system in vehicle applications is reported by Patel and Doyle [3] in 1976. They presented a concept to recover energy from the exhaust gas of a Mack 676 diesel engine mounted on a long-haul truck, declaring a gain of $13 \%$ in net power output compared to the single baseline engine, when operating at peak load conditions. DiBella et al. [4] reported for the same system, after tests, a final possible $12.5 \%$ improvement in fuel consumption for a Class 8 long-haul vehicle, using mechanical coupling to supply the recovered energy to the engine crankshaft.

Nelson [5], in 2009, reported a presentation regarding Cummins ORC-related activity on HDDE, proposing to recover mainly EGR and exhaust heat, concluding that the development of efficient SCR after-treatment systems is supposed to decrease the benefit of an ORC fitted on the EGR. Cummins claimed a potential improvement in engine total efficiency between 5 and $8 \%$.

Also Daimler and Detroit Diesel, in the frame of the DOE (U.S. Department of Energy) Super Truck Program, investigated the possibility of recovering exhaust heat from a truck HDDE [6]. A system recovering EGR and exhaust gas using ethanol as working fluid is proposed. Regarding the expander choice, piston, and scroll expanders are 
selected, due to their ability of handling two-phase expansion, in comparison with turbo-expanders. Different vehicle-cooling strategies, components packaging and weight issues have been investigated.

Also Bosch presented simulation and experimental results of an ORC waste heat recovery system for commercial vehicles applications [7, 8]. In this case, a piston and a turbine expander have been proposed. Exhaust gas and EGR heat sources have been recovered in a parallel configuration. Water-steam, ethanol, MM (hexamethyldisiloxane), R-245fa, and toluene have been evaluated as working fluids for the turbine case.

The commercial vehicles manufacturer Hino reported the results of the design and tests of a Rankine cycle used to recover heat from the coolant of an HDDE for truck applications [9]. The energy of the cooling circuit has been increased collecting the heat from exhaust and EGR, thus increasing coolant temperature up to $105{ }^{\circ} \mathrm{C}$. $7.5 \%$ improvement of fuel economy has been obtained from tests using Hydro-Fluoro-Ether (HFE) as working fluid.

Also Ricardo plc worked on an ORC system to recover EGR and exhaust gas from a $288-\mathrm{kW}$ Volvo HDDE for trucks applications, using as working fluid an ethanolwater mixture [10]. Thermodynamic system analysis, components commissioning, control strategies implementation and testing have been performed. A piston expander has been chosen as expansion machine, and engine mechanical coupling for the produced energy utilization has been proposed.

Ricardo plc has also worked on a double-deck dieselhybrid bus (2.4-L, EURO IV turbocharged diesel engine), with the purpose of recovering coolant and exhaust heat with two separate ORC architectures, in the frame of the TERS project (Thermal Energy Recovery System) [11-15]. A scroll expander technology and R-245fa as working fluid have been proposed. From vehicle tests using market-ready components, a $6 \%$ fuel economy has been achieved on a typical city bus driving cycle, being reduced to $2.7 \%$ considering that in the hybrid bus the internal combustion engine is switched on only for approximately $45 \%$ of the time in a generator mode. Additional benefits could be reached when using a cascaded ORC layout, or so-called dual-loop, recovering the condensing heat from the topping exhaust ORC cycle in order to preheat the lower-pressure ORC loop used for the coolant heat recovery.

Some additional studies have been carried out also by academic institutions. For example, Katsanos et al. [16], reported a theoretical study of a steam Rankine cycle to recover heat from a HDDE for trucks, considering also evaporator design and the possibility of recovering exhaust gas and EGR. They demonstrated a possible $7.5 \%$ improvement in brake-specific fuel consumption (BSFC). In their study, they also considered the impact of fitting the bottoming cycle on the vehicle-cooling system, pointing out the need of increasing $20 \%$ the radiator heat rejection capabilities when using the ORC. Hountalas et al. [17] considered also the possibility of recovering CAC heat, using water-steam or R-245ca, and declaring between 9 and $11.3 \%$ improvement in BSFC. Radiator heat rejection capabilities are considered also in this study. Katsanos et al. [18] improved the previous studies considering also a parametric analysis and different engine loads (from 25 to $100 \%$ ).

Latz et al. [19] proposed some experimental results about a water-based Rankine cycle used to recover heat from the EGR of a 12.8-L HDDE engine installed on a testbench. Deionized water, a two-cylinder piston expander and a EGR boiler prototype have been proposed, and $10 \%$ thermal efficiency has been declared for the ORC system.

Many studies reported in literature about ORC waste heat recovery for vehicles are related to passenger cars (diesel or gasoline), on-highway trucks, stationary power generation, or marine applications, but off-highway applications, as earth-moving machines or agricultural tractors, are not commonly investigated. Even though engine and powertrain thermal management in off-highway vehicles is very problematic, due to low ram air effect for cooling purpose and high parasitic fan power consumption, the operating profile is very suitable for waste heat recovery bottoming cycles implementation, due to the high engine speed and load stable conditions, and the availability of valuable mediumhigh temperature heat in the exhaust and EGR.

For these reasons, the proposed work investigates the possibility of recovering heat from exhaust gas and EGR of a commercial HDDE for an agricultural tractor, considering also the impact of fitting the ORC system on the radiator dimensions and, thus, on the vehicle-cooling system performance, an issue often not considered in literature. Two different heat sink configurations are investigated: a highertemperature (HT) engine cooling circuit or a lower-temperature ORC-only additional cooling circuit (LT).

The performance of the different ORC architectures, and of the proposed cooling strategies, is investigated through the use of a process simulation model developed in engineering equation solver [20], while cycle parameters are optimized using a genetic algorithm [21] and a NelderMead simplex algorithm [22], with the purpose of maximizing the overall powertrain brake-specific fuel consumption benefit and to assess the possible power output benefit that can be expected.

\section{Reference engine and design point choice}

The reference engine considered in this study is a heavyduty direct injection six cylinders in-line diesel engine with a brake power output of $302 \mathrm{~kW}$. The engine configuration 
is two-stage turbocharged with intercooling and is fulfilling the Tier 4 final emissions regulation for off-highway vehicles, using cooled high-pressure EGR and a complete after-treatment system composed by diesel oxidation catalyst (DOC), diesel particulate filter (DPF) and selective catalytic reduction (SCR) with urea injection.

In order to choose the most appropriate design point for the ORC system, it is necessary to investigate the application-specific operating profile. An example of engine speed $(N)$ and engine torque $(\tau)$ profiles for a typical agricultural tractor operating cycle is reported in Fig. 1, in the form of histograms, as percentage of time spent in a certain speed or torque range. Data are obtained and elaborated from EPA non-regulatory non-road duty cycle examples [23].

From the typical operating cycle, it is possible to observe how the engine spends most of the time at full load and medium- to high-speed conditions, thus leading to the availability of a high amount of exhaust gas at mediumhigh temperature, suitable for heat recovery through the use of bottoming cycles. For this reason, the design point for the ORC system calculations has been chosen in this engine operating range.

The data used to carry out the ORC implementation analysis are experimental data at design load conditions and are reported in Table 1.

The exhaust gas thermal power is calculated imposing as lower cooling limit $90^{\circ} \mathrm{C}$, considering a low-sulphur content diesel fuel, in order to avoid acid condensation problems in the ORC exhaust heat exchanger.

Temperature data for the exhaust line of the reference engine are available only until the low pressure turbine outlet, not considering the after-treatment system. However, from what reported by Qiu et al. [24], and analysing some other steady-state proprietary Ricardo HDDE test data, in which temperatures in the after-treatment are measured, it is possible to assume that there is no temperature change over the after-treatment system, especially in the engine high speed and torque range considered in this study.

\section{Engine Speed (N)}

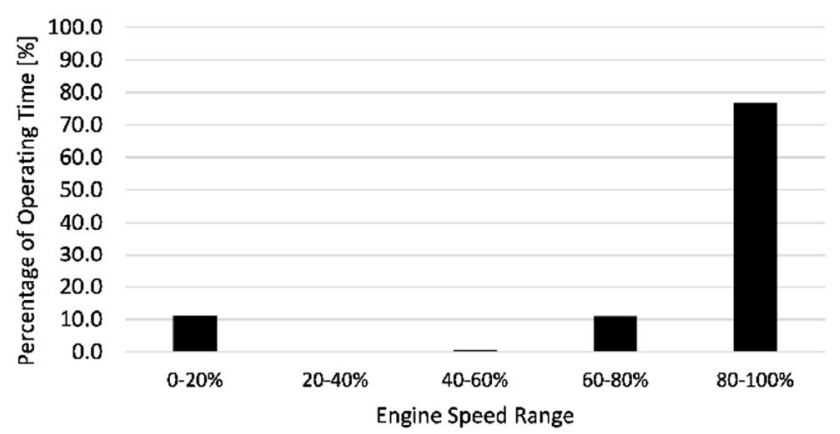

\section{Modelling and methodology}

\section{Organic Rankine cycle (ORC)}

In this work, two ORC architectures are considered: a simple evaporator configuration (SC, simple cycle) to recover heat from tail-pipe exhaust gas, and a parallel evaporator configuration (PC, parallel cycle) to recover heat both from exhaust and EGR gas.

The engine and the main ORC components, evaporator, condenser, pump (P) and expander (EXP) can be observed in Fig. 2a-d, which reports both the simple cycle (SC) and the parallel cycle (PC) ORC architectures, and the two different heat sink configurations: the indirect condensation 1 (IC 1), using the engine high-temperature cooling circuit, and the indirect condensation 2 (IC 2), using a dedicated ORC lower-temperature circuit.

The evaporators are placed after the after-treatment system and instead of the EGR cooler. In this preliminary study, the increased back-pressure effect of the boilers on the engine is not considered.

The two investigated heat sink solutions can also be observed in schemes reported in Fig. 2a-d: indirect condensation 1 (IC1), a configuration using the engine and EGR high-temperature cooling circuit as heat sink for the ORC system, and indirect condensation 2 (IC2), a configuration using a lower-temperature cooling circuit with the purpose of increasing the net power output of the bottoming cycle, allowing a higher enthalpy drop in the expander. In this second case, an additional radiator is needed. The two ORC architectures are evaluated with both heat sink configurations, for a total of four cases, as reported in the figures.

The main data for the heat sink configurations are reported in Table 2. The coolant is a mixture of water and ethylene-glycol with a 50\% mass composition for the two components. The mass flow, in the IC2 case, has been considered as a variable in the optimization process, and the ORC condenser inlet temperature has been fixed to

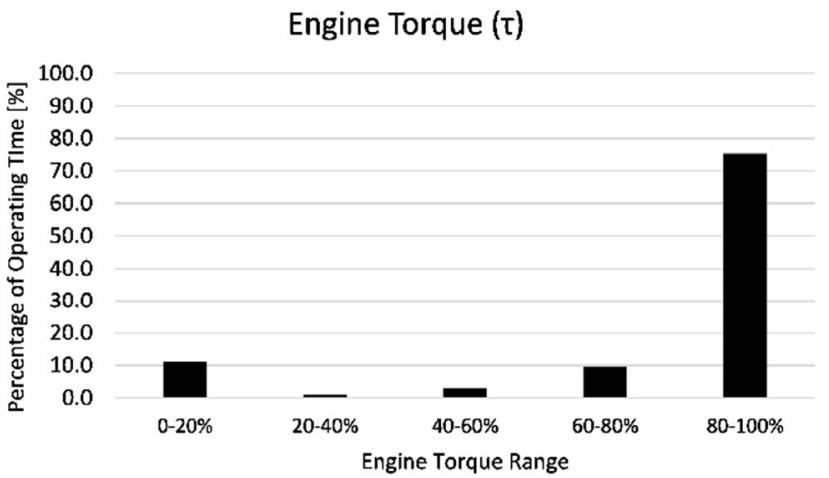

Fig. 1 Engine speed and torque profiles for the EPA field work operating cycle 
Table 1 Engine-ORC design point

\begin{tabular}{llll}
\hline Engine-ORC design point & Symbol & Unit & Value \\
\hline Engine brake power & $P_{\text {eng }}$ & $(\mathrm{kW})$ & 302 \\
Engine speed & $N$ & $(\mathrm{rpm})$ & 2000 \\
Engine torque & $\tau$ & $(\mathrm{Nm})$ & 1443 \\
Exhaust gas mass flow rate & $\dot{m}_{\text {exh }}$ & $\left(\mathrm{kg} \mathrm{s}^{-1}\right)$ & 0.36 \\
Exhaust gas temperature (after low pressure turbine) & $T_{\text {exh }}$ & $\left({ }^{\circ} \mathrm{C}\right)$ & 509 \\
Exhaust gas thermal power (cooling limit to $\left.90^{\circ} \mathrm{C}\right)$ & $\dot{Q}_{\text {exh }}$ & $(\mathrm{kW})$ & 186 \\
EGR gas mass flow rate & $\dot{m}_{E G R}$ & $\left(\mathrm{~kg} \mathrm{~s}^{-1}\right)$ & 0.12 \\
EGR gas temperature (EGR cooler inlet) & $T_{E G R, I N}$ & $\left({ }^{\circ} \mathrm{C}\right)$ & 699 \\
EGR gas temperature (EGR cooler outlet) & $T_{E G R, O U T}$ & $\left({ }^{\circ} \mathrm{C}\right)$ & 145 \\
EGR cooler thermal power & $\dot{Q}_{E G R}$ & $(\mathrm{~kW})$ & 81 \\
\hline
\end{tabular}

$50{ }^{\circ} \mathrm{C}$. The thermodynamic properties for the coolant mixture, as well as the ORC working fluids, are obtained from engineering equation solver (EES) internal database [20].

The following assumptions have been used in the process simulation model:

- $\quad$ pressure drops and heat losses have not been considered in the components and in the pipes;

- $\quad$ pump isentropic efficiency, $\eta_{i s, P}$, has been set to $70 \%$;

- expander isentropic efficiency, $\eta_{i s, E}$, has been set to $80 \%$, considering the possibility of using a radial expander, due to the stable operating profile;

- expander mechanical efficiency, $\eta_{\text {mech, }}$, has been set to $85 \%$, considering possible mechanical coupling with the engine crankshaft using a belt. Electrical coupling could also be assumed, in first approximation, to have a similar efficiency value when considering the electric generator and a driving belt;

- heat exchangers are counter-flow, divided in singlephase and two-phase zones and modelled with fixed boundaries technique;

- a sub-cooling degree, $\Delta T_{\text {sub-cool }}$, of $2{ }^{\circ} \mathrm{C}$ has been imposed at the outlet of the condenser in order to obtain working fluid always in a liquid state at the pump inlet and avoid cavitation problems. A fluid reservoir is not modelled in this preliminary study;

- in first approximation, exhaust gas and EGR gas are assumed to have the same properties of dry air;

- the circulator pumps of the cooling circuits are not considered in the overall power balance;

Condensation pressure, $p_{\text {cond }}$, as well as the pressure ratio over the pump, $P R$, are imposed, and the evaporation pressure can be easily calculated as:

$p_{\text {evap }}=p_{\text {cond }} \cdot P R$

Referring to Fig.3, the pressure at the pump inlet, $p_{1}$, is fixed as condensing pressure, while the pressure at the pump outlet, $p_{2}$, is the evaporation pressure, and it is fixed once the pressure ratio is chosen (independent variable of the optimization process). Using EES, all the thermodynamic properties of the fluid at point 1 can be calculated knowing $T_{1}$ and $p_{1}$.

The pump isentropic specific work, $w_{i s, P}$, can be calculated then as:

$w_{i s, P}=v_{1} \cdot\left(p_{2}-p_{1}\right)$

Once the isentropic efficiency of the pump, $\eta_{i s, P}$, is fixed, the specific work at the pump can be calculated as:

$w_{P}=\frac{w_{i s, P}}{\eta_{i s, P}}$

The pump required power is then calculated multiplying for the working fluid mass flow, $\dot{m}_{w f}$, as:

$P_{P}=w_{P} \cdot \dot{m}_{w f}$

The specific enthalpy at point 2 (pump outlet) can be calculated as:

$h_{2}=h_{1}+w_{P}$

All the other thermodynamic properties can be obtained for point 2 , knowing the pressure, $p_{2}$, and the specific enthalpy, $h_{2}$. The same can be done for point 3 (knowing $p_{3}$ and $x_{3}$ ), for point 4 (knowing $p_{4}$ and $x_{4}$ ) and point 5 (imposing the superheating temperature $\Delta T_{s h}$, thus $T_{5}$, and $p_{5}$ ), and once the pressure drops in the preheater (2-3), evaporator (3-4) and super-heater (4-5) are imposed (in this case no pressure drops are considered). The heat exchanged with the heat source is calculated as an energy balance, with the purpose to obtain the heat source temperatures in the various points dividing the heat exchanger in preheater, evaporator and super-heater, in order to evaluate the pinch points in every location.

For the expander, the specific entropy at point $6_{\text {is }}, s_{6, \text { is }}$ (isentropic expansion) is considered equal to the one at point $5\left(s_{5}\right)$ and the other properties a point $6_{\text {is }}$ are calculated knowing pressure, $p_{6, i s}$, and entropy, $s_{6, i s}$. The isentropic specific work extracted with the expander is then calculated as: 
Fig. 2 Simple cycle (SC) and indirect condensation1 (IC 1) architecture (a). Parallel cycle (PC) and indirect condensation 1 (IC 1) architecture (b). Simple cycle (SC) and indirect condensation 2 (IC 2) architecture (c). Parallel cycle (PC) and indirect condensation 2 (IC 2) architecture (d)

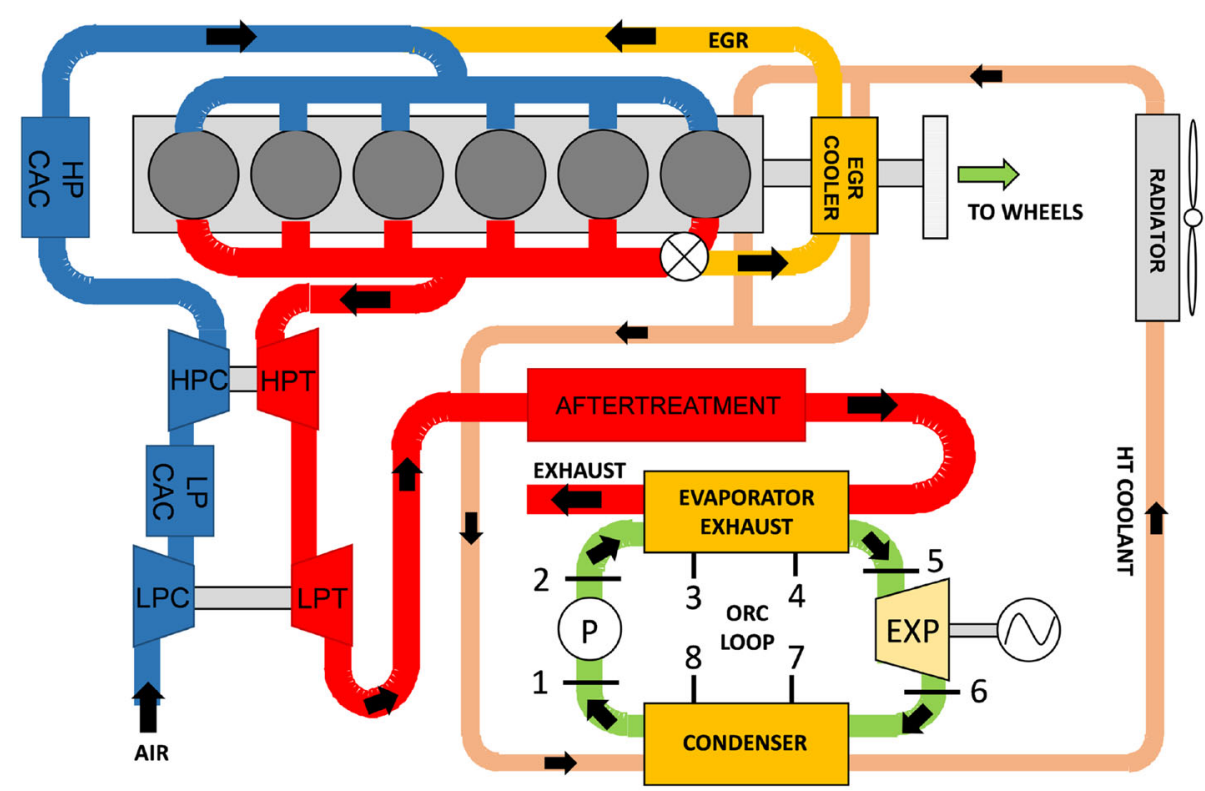

(a)

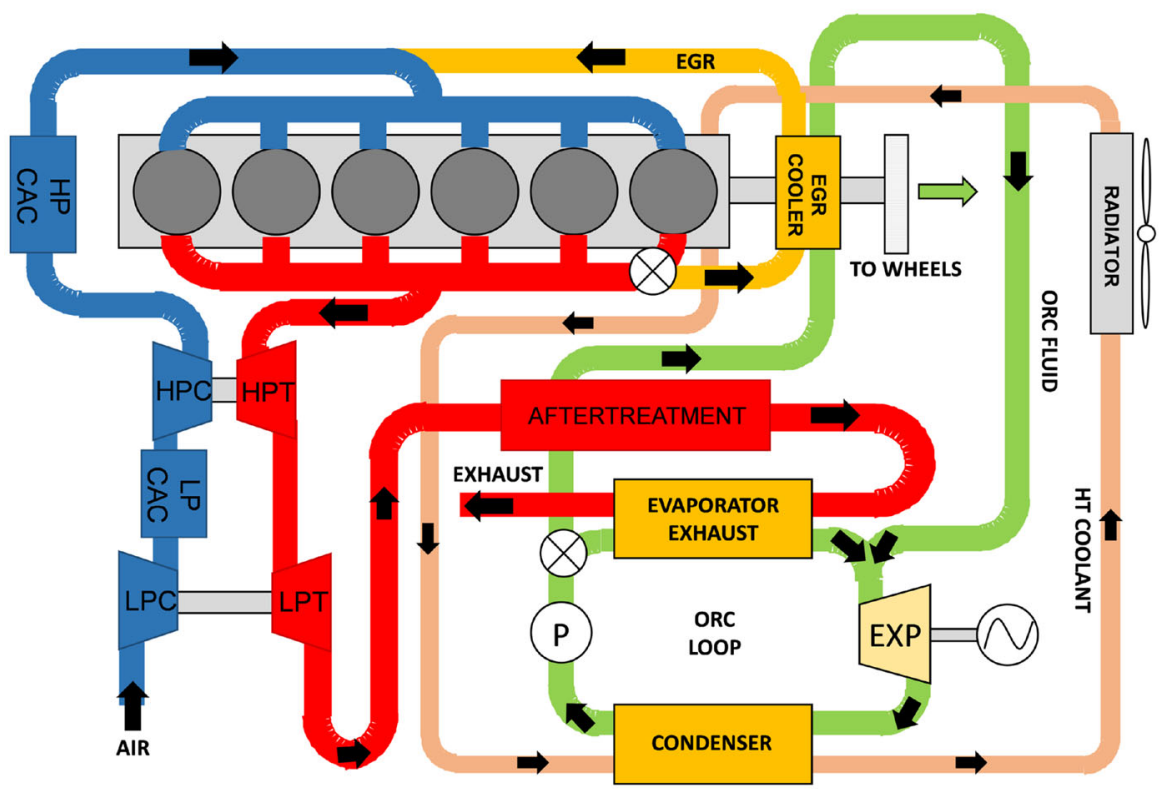

(b) $w_{i s, E}=h_{5}-h_{6, i s}$

As done for the pump, imposing the isentropic efficiency of the expander, $\eta_{i s, E}$, it is possible to obtain the actual expander specific work:

$w_{E}=w_{i s, E} \cdot \eta_{i s, E}$

The expander power is then obtained as done for the pump: $P_{E}=w_{E} \cdot \dot{m}_{w f}$

Then the specific enthalpy at point 6 , expander outlet, is calculated as:
$h_{6}=h_{5}-w_{E}$

The other thermodynamic properties for point 6 can be calculated from specific enthalpy, $h_{6}$, and pressure, $p_{6}$.

A simple procedure has then been implemented to control the position of points 6 and 7, depending if the end of the expansion process is inside or outside the dome $\left(x_{6}\right)$, and then fixing the positions of point 7 (vapour quality, $x_{7}$ ) of consequence. Subsequently the thermodynamic properties can be calculated from $p_{7}$ and $x_{7}$.

The heat exchangers (boiler and condenser) have been analysed considering three subsections: preheater (2-3), 
Fig. 2 continued

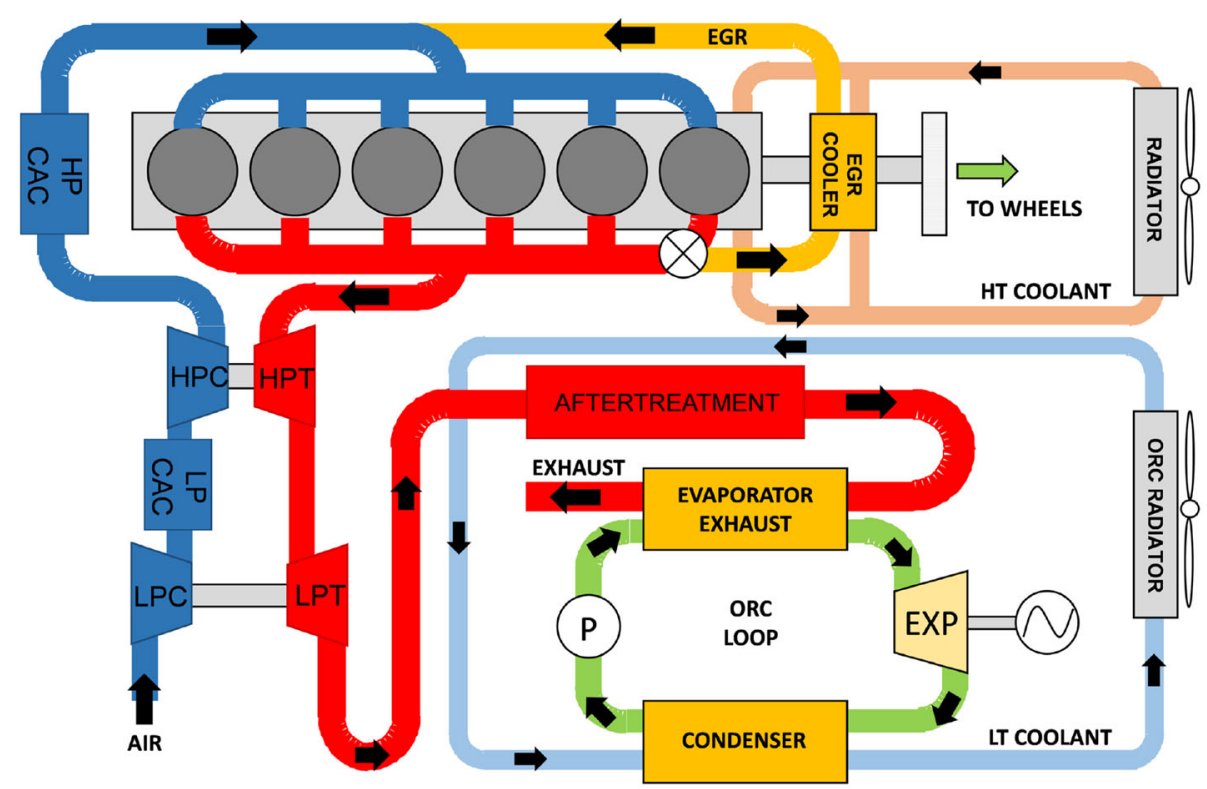

(c)

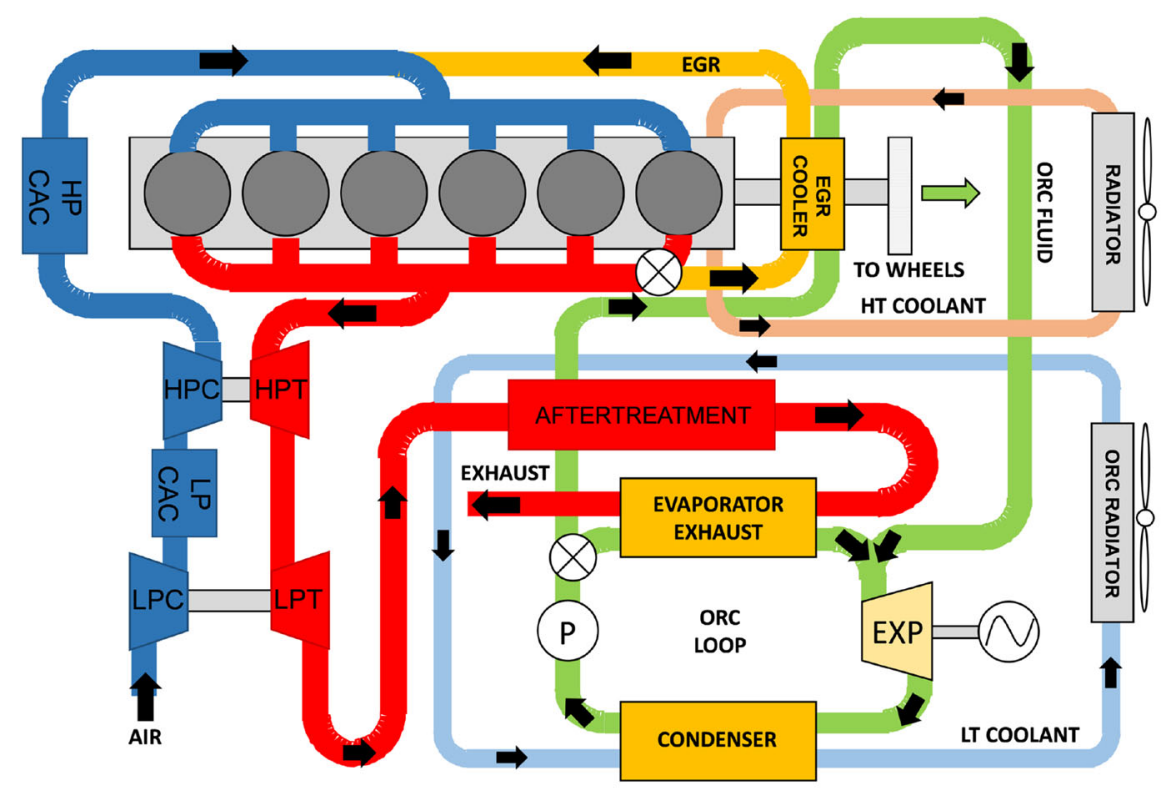

(d)

Table 2 Heat sink data

\begin{tabular}{lllll}
\hline Heat sink data & Symbol & Unit & IC1 & IC2 \\
\hline Coolant mass flow rate & $\dot{m}_{c f}$ & $\left(\mathrm{~kg} \mathrm{~s}^{-1}\right)$ & 3.2 & var. \\
Coolant temperature at the ORC condenser inlet & $T_{c f, I N}$ & $\left({ }^{\circ} \mathrm{C}\right)$ & 93.6 & 50 \\
\hline
\end{tabular}

evaporator (3-4) and super-heater (4-5) for the boiler, and de-super-heater (6-7), condenser (7-8) and sub-cooler (81) for the condenser. For every subsection, heat balances are applied and the temperatures of exhaust gas, EGR and coolant are calculated at every point, with the purpose of subsequently evaluating pinch point constraints $\left(\Delta T_{P P, \min }=10^{\circ} \mathrm{C}\right)$.

A scheme of the described processes can be observed on a T-s diagram in Fig. 3, for a simple cycle (SC) configuration, while, for a parallel cycle (PC) configuration, 


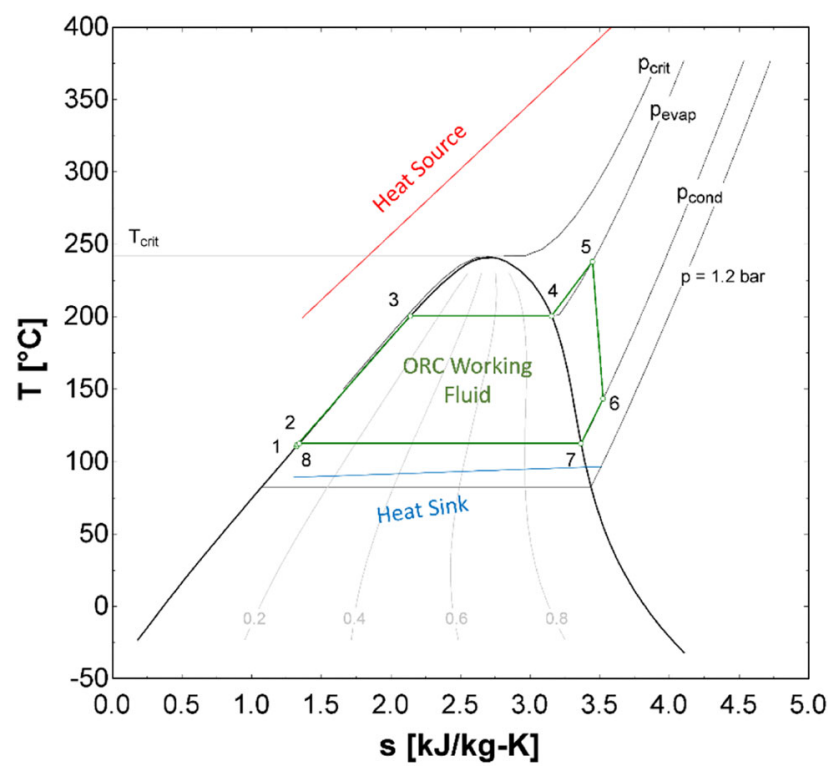

Fig. 3 T-S diagram scheme for a simple cycle (SC) ORC architecture

simply the evaporation process is modelled in the same way for the second boiler.

The overall cycle performance comparison has been carried out considering:

- ORC net power output (considering mechanical efficiency also in the balance):

$$
P_{O R C, \text { net }}=P_{E}-P_{P}
$$

- ORC efficiency:

$\eta_{\text {ORC }}=\frac{P_{\text {ORC,net }}}{\dot{Q}_{\text {ORC }, I N}}$

with $\dot{Q}_{O R C I N}[\mathrm{~kW}]$ the heat recovered by the cycle;

- brake-specific fuel consumption (BSFC) of the combined engine-ORC system (\%):

$$
B S F C_{\text {eng }+ \text { ORC }}=\frac{\dot{m}_{f}}{P_{\text {eng }+ \text { ORC }}} \cdot 100
$$

with $P_{\text {eng }+ \text { ORC }}[\mathrm{kW}]$ the net power output of the engineORC combined system.

- BSFC improvement (compared to baseline engine) (\%):

$$
B S F C_{\text {impr }}=\frac{\left(B S F C_{\text {eng }}-B S F C_{\text {eng }+O R C}\right)}{B S F C_{\text {eng }}} \cdot 100
$$

- ORC system rejected heat $(\mathrm{kW})$ at the condenser:

$$
\dot{Q}_{\text {ORC }, \text { out }}=\dot{Q}_{\text {de-superh }}+\dot{Q}_{\text {cond }}+\dot{Q}_{\text {sub-cool }}
$$

Moreover, some additional performance indexes have been used to investigate the overall cycle as well as individual components performance and dimensions [25]. The performance indexes used are shown in Table 3.

The last parameter presented in the table above gives an idea of the dimensions, and thus the cost, of the heat transfer equipment, and is calculated using the log mean temperature difference method (LMTD) [26].

\section{Heat sink and radiator}

The radiator has also been modelled using EES. The configuration is a single-pass cross-flow compact fin and plate heat exchanger, with rectangular coolant plate flow areas and triangular fins geometry, in which the coolant flows only in the direction from the top to the bottom of the heat exchanger, in a so-called $I$ configuration. The air is considered to be homogeneously distributed over the radiator frontal area, as the coolant in the pipes.

The modelling theory guidelines have been taken mainly from Cowell [27]. The coolant is considered to be a mixture of water and ethylene-glycol ( $0.5 / 0.5$ in mass composition), while the coolant heat transfer and pressure drop correlations have been obtained from EES internal procedures, based on laminar or turbulent flow regimes. For the

Table 3 ORC performance parameters

\begin{tabular}{lll}
\hline Parameter & Reference component & Description \\
\hline$P_{\text {ORC,net }}$ & ORC System & ORC net power output \\
$\eta_{\text {ORC }}$ & ORC System & ORC efficiency \\
$B S F C_{\text {impr }}$ & Combined system & BSFC improvement compared to baseline engine \\
$\dot{Q}_{\text {ORC }, \text { OUT }}$ & ORC system & ORC rejected heat in the condenser \\
$\sum_{i} U_{i} A_{H X, i}=\frac{1}{\dot{m}_{\text {exh } / E G R}} \sum_{i}\left(\frac{\dot{Q}_{H X, i}}{\Delta T_{L M T D, i}}\right)$ & Heat exchangers & Sum of the conductance \\
& & of the HXs (global surface index) \\
& & per unit recovered mass flow
\end{tabular}


Fig. 4 Radiator fin-and-plate dimensions (a) and main geometry dimensions (b). Elaborated from [27] (a)

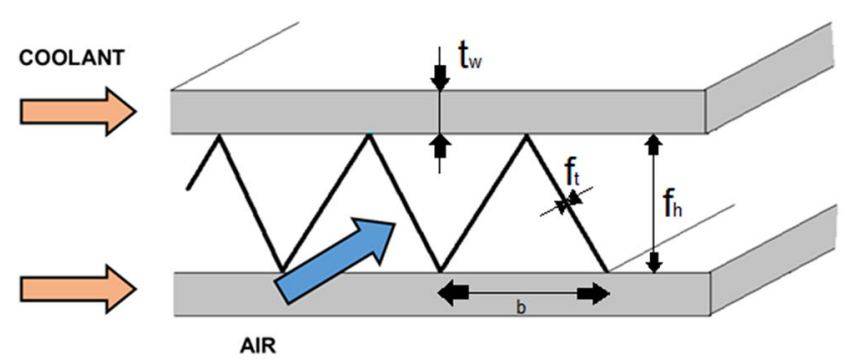

(b)

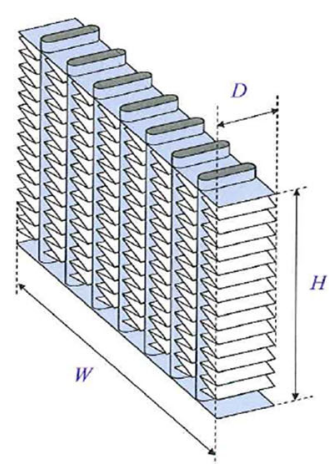

air side, the Colburn factor and friction coefficient have been obtained from Cowell [27] and used as a lookup table in the calculations. The performance of the radiator, in term of heat rejection capabilities based on main component dimensions supplied as inputs (Fig. 4), are calculated based on the $\varepsilon-N T U$ method [26].

In particular, for the coolant plates side, the EES implemented procedure "DuctFlow" [28] has been used to obtain the average convective heat transfer coefficient. This procedure has been considered more accurate than using the Dittus-Boelter (fully turbulent flow) correlation [29]. Indeed "DuctFlow" determines whether the flow is laminar or turbulent (or transitional between 2300 and $3000 \mathrm{Re}$ ) and applies the right correlations regarding heat transfer and pressure drops.

For the air side, the Colburn factor and the friction coefficient, together with the specification of the main geometry parameters, have been used with the final purpose of investigating the heat transfer and the air pressure drop over the radiator core geometry.

In particular, once the overall heat transfer coefficient $U A$ has been calculated (neglecting the conductance in the plates thickness), the $\varepsilon$-NTU method [26] has been applied to obtain the radiator effectiveness and then estimate the heat transfer rate between coolant and air sides.

The procedure is applied using the coolant and air mean temperature values, between inlet and outlet, but since the outlet temperatures of the two flows are not known at the beginning, an iterative process has been implemented exploiting the solver capabilities of EES.

For the estimation of the fan parasitic power consumption, the fan static efficiency, $\eta_{f a n}$, has been imposed to $60 \%$, considering big heavy-duty cooling fan applications. This number has been compared with some data from multi-wing fan manufacturer software [30] obtaining a good match for big diameters $(700-800 \mathrm{~mm})$ fan models.

The fan power consumption has been estimated with following formula:
$P_{a b s, f a n} \cong \frac{\dot{m}_{\text {air }} \cdot p_{\text {air }}}{\rho_{\text {air }, \text { avg }} \cdot \eta_{\text {fan }}}$

considering the required cooling air mass flow $\dot{m}_{\text {air }}$, the total radiator core air side pressure drop, $\Delta p_{\text {air }}$, the average air density, $\rho_{\text {air,avg }}$, and the fan efficiency, $\eta_{\text {fan }}$.

The radiator fins density has been kept fixed to 8 fins/ inch, considered suitable for off-highway applications operating in dusty conditions, and the material is aluminium.

As first step, since no real data were available, the baseline engine radiator (without ORC) has been sized, considering core height $(\mathrm{H})$, width $(\mathrm{W})$ and depth $(\mathrm{D})$, in order to keep the frontal area $1 \mathrm{~m}^{2}$ and reject $202.5 \mathrm{~kW}$ heat to the ambient, to cool the cooling fluid from a radiator inlet temperature of $95.7-84{ }^{\circ} \mathrm{C}$ (engine inlet temperature), as required during Ricardo testing campaigns. The cooling air inlet temperature has been imposed to the average fixed value of $50{ }^{\circ} \mathrm{C}$, considering an ambient temperature of $40{ }^{\circ} \mathrm{C}$ to simulate particularly critical hot conditions for the cooling package, and assuming the radiator in series after $\mathrm{CAC}$, oil cooler and air conditioning condenser, in a traditional cooling package configuration. For the air conditioning condenser, $5 \mathrm{~kW}$ average heat rejection has been assumed, as reported in [31], in order to estimate the temperature drop over the $\mathrm{AC}$ cooler and the temperature at the engine radiator inlet. The data for the baseline radiator are reported in Table 4.

When fitting the ORC, two different heat sink configurations have been considered for the two cases IC1 (indirect condensation 1) and IC2 (indirect condensation 2). The two configurations are influencing the cooling air temperature at the inlet of the radiator, and thus, the radiator performance. The schemes, together with a simplified vehicle sketch, are reported in Fig. 5, to give an idea of how the design could look like.

The configuration $(a)$ is similar to the baseline and is the most compact, since the same cooling circuit is used to 
Table 4 Baseline engine radiator data

\begin{tabular}{llll}
\hline Baseline engine radiator data & Symbol & Unit & Value \\
\hline Coolant volume flow & $\dot{V}_{c f}$ & $\left(\mathrm{~m}^{3} \mathrm{~s}^{-1}\right)$ & 4.8 \\
Coolant radiator inlet temperature & $T_{c f, \text { air }, I N}$ & $\left({ }^{\circ} \mathrm{C}\right)$ & 95.7 \\
Cooling air volume flow & $\dot{V}_{\text {air }}$ & $\left(\mathrm{m}^{3} / \mathrm{s}\right)$ & 11.8 \\
Cooling air radiator inlet temperature (after CAC and AC HX) & $T_{\text {air,rad,IN }}$ & $\left({ }^{\circ} \mathrm{C}\right)$ & 50 \\
Radiator heat rejection & $\dot{Q}_{\text {rad }}$ & $(\mathrm{kW})$ & 202.5 \\
Radiator height & $H$ & $(\mathrm{~m})$ & 1.13 \\
Radiator width & $W$ & $(\mathrm{~m})$ & 0.89 \\
Radiator depth & $D$ & $(\mathrm{~m})$ & 0.08 \\
Radiator core frontal area & $A_{f, \text { rad }}$ & $\left(\mathrm{m}^{2}\right)$ & 1 \\
Radiator core volume & $V_{\text {rad }}$ & $\left(\mathrm{m}^{3}\right)$ & 0.08 \\
Fan power consumption & $P_{\text {fan }}$ & $(\mathrm{kW})$ & 21 \\
\hline
\end{tabular}
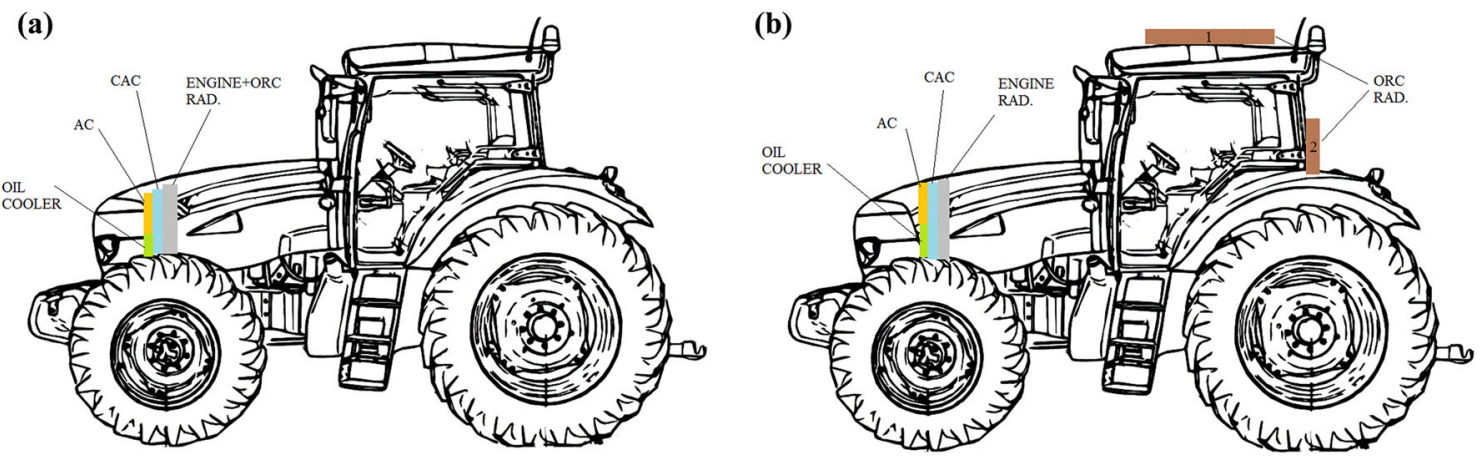

Fig. 5 Heat sink configurations IC1 (a) and IC2 (b)

cool both engine and ORC, and the coolant is then cooled in a combined engine-ORC radiator. However, the high temperature of the cooling air at the inlet of the combined radiator decreases the heat rejection capabilities of the heat exchanger, thus requiring higher dimensions and more cooling air volume flow, with increased fan parasitic power consumption when increasing the heat that must be rejected adding the ORC system. An additional ORC-only separated radiator, positioned in series after the engine radiator, would have been probably affected by too high cooling air inlet temperature. For this reason, this configuration has not been considered.

The configuration $(b)$ needs additional piping and more complicated system layout. The position of the ORC radiator behind the cabin can create visibility problems when the tractor works in reverse direction or when controlling PTOs. The roof-top position could be more interesting and could lead to less issues (resistance of the cabin must be assessed and components probably reinforced). However, this configuration benefits from the lower temperature of the cooling air, which has not to pass through the cooling package before cooling the ORC radiator, and can, in first approximation, be considered at the same
Table 5 Heat sink study configurations

\begin{tabular}{lll}
\hline Case & Configuration ORC-heat sink & Heat sink position \\
\hline 1 & Simple cycle (SC)-IC1 & a \\
2 & Parallel cycle (PC)-IC1 & a \\
3 & Simple cycle (SC)-IC2 & b \\
4 & Parallel cycle (PC)-IC2 & b \\
\hline
\end{tabular}

temperature of ambient air. However, an additional electrically driven fan must be considered in this case, thus impacting the overall vehicle power balance.

In total, four cases have been considered for the heat sink study of the combined engine-ORC system (Table 5).

\section{Working fluid selection}

A literature review of the most used ORC fluids for medium or high temperature waste heat recovery has been carried out. After the first step, a final list of ten fluids has been finalized, considering only the fluids which fulfilled some requirements on the base of the NFPA 704 classification, from the National Fire Protection Association [32], and on the base of the low global warming potential at 
Table 6 Working fluids evaluated in the study

\begin{tabular}{|c|c|c|c|c|c|c|c|}
\hline Working fluid & $\begin{array}{l}T_{c} \\
\left({ }^{\circ} \mathrm{C}\right)\end{array}$ & $\begin{array}{l}p_{c} \\
\text { (bar) }\end{array}$ & $\begin{array}{l}T_{\text {boil }} \\
\left({ }^{\circ} \mathrm{C}\right)\end{array}$ & $\begin{array}{l}T_{\text {freeze }} \\
\left({ }^{\circ} \mathrm{C}\right)\end{array}$ & Health hazard $(\mathrm{H})$ & Flammability hazard $(\mathrm{F})$ & GWP (100) \\
\hline Ethanol & 241.6 & 62.7 & 78.5 & -114.2 & 0 & 3 & $\mathrm{n} / \mathrm{a}$ \\
\hline Methanol & 239.5 & 81 & 64.5 & -97.6 & 1 & 3 & 2.8 \\
\hline Toluene & 318.6 & 41.3 & 110.6 & -95.2 & 2 & 3 & 2.7 \\
\hline Cyclopentane & 238.6 & 45.7 & 49.3 & -93.5 & 1 & 3 & $\mathrm{n} / \mathrm{a}$ \\
\hline MDM & 290.9 & 14.2 & 152.5 & -86 & 0 & 2 & $\mathrm{n} / \mathrm{a}$ \\
\hline Acetone & 235 & 47 & 56.1 & -94.7 & 1 & 3 & 0.5 \\
\hline $\mathrm{R}-141 \mathrm{~b}$ & 204.4 & 42.1 & 32.1 & -103.5 & 2 & 1 & 725 \\
\hline $\mathrm{R}-123$ & 183.7 & 36.6 & 27.8 & -107.2 & 2 & 0 & 77 \\
\hline $\mathrm{R}-245 \mathrm{fa}$ & 154 & 36.5 & 15.1 & -102.1 & 2 & 1 & 1030 \\
\hline Water-steam & 374 & 220.6 & 100 & 0 & 0 & 0 & $<1$ \\
\hline
\end{tabular}

100 years (GWP 100), in order to use fluids not very harmful for the environment [33]. The limits for the health hazard $(\mathrm{H})$ have been set to two, the one for flammability $(F)$ to three and the GWP 100 to 1300 . The freezing point limit has been assumed to be $0{ }^{\circ} \mathrm{C}$ (water steam) to avoid fluid freezing problems in cold ambient conditions. The final list of fluids evaluated is reported in Table 6, together with the main properties obtained from NIST REFPROP [34].

\section{Optimization procedure}

For all the four cases evaluated, the chosen ten fluids have been thermodynamically assessed in order to obtain the best BSFC improvement $\left(B S F C_{i m p r}\right)$ for the combined engine-ORC system.

First of all, the independent variables for the optimization process have been identified and are reported in Table 7, divided for type of cycle architecture.

The cooling fluid mass flow variable is optimized only in heat sink layout IC2, because in the layout IC1, the parameter is fixed as the same for the engine cooling system.
As a second step, the constraints for the optimization process have been identified and are presented in Table 8 . Some considerations can be done about the imposed constraints:

- the pinch point value of $10{ }^{\circ} \mathrm{C}$ has been considered as a trade-off between heat exchanger performance and cost-dimensions;

- the working fluid evaporation pressure has been limited to 30 bar or $90 \%$ of the fluid critical pressure due to safety reasons and possible fluid chemical instability;

- the working fluid condensing pressure has been imposed to be higher than 1.2 bar in order to avoid ambient air leaking into the system and expensive sealing;

- the evaporating and condensing temperatures have been imposed higher than $50{ }^{\circ} \mathrm{C}$ in order to avoid inverse heat transfer during particularly hot ambient conditions;

- the exhaust gas temperature at the outlet of the evaporator has been limited to $90{ }^{\circ} \mathrm{C}$ in order to avoid acid condensation and corrosion problems (low sulphur content diesel fuel assumed);

- the EGR cooler gas outlet temperature has been fixed to $145^{\circ} \mathrm{C}$ in order to fulfil combustion requirements for the engine;
Table 7 Independent variables for the optimization procedure

\begin{tabular}{llll}
\hline Independent variable & Unit & Simple cycle (SC) & Parallel cycle (PC) \\
\hline Working fluid mass flow & $\left(\mathrm{kg} \mathrm{s}^{-1}\right)$ & $\dot{m}_{w f}$ & $\dot{m}_{w f}$ \\
Condensing pressure & $(\mathrm{bar})$ & $p_{\text {cond }}$ & $p_{\text {cond }}$ \\
Pressure ratio & $(-)$ & $P R$ & $P R$ \\
Superheating degree in the ORC exhaust circuit & $\left({ }^{\circ} \mathrm{C}\right)$ & $\Delta T_{s h, e x h}$ & $\Delta T_{s h, e x h}$ \\
Superheating degree in the ORC EGR circuit & $\left({ }^{\circ} \mathrm{C}\right)$ & - & $\Delta T_{s h, E G R}$ \\
Cooling fluid mass flow & $(\mathrm{kg} / \mathrm{s})$ & $\dot{m}_{c f}$ & $\dot{m}_{c f}$ \\
Working fluid rate in the ORC EGR circuit & $(\%)$ & - & $a_{E G R}$ \\
\hline
\end{tabular}


Table 8 Constraints for the optimization procedure

\begin{tabular}{|c|c|c|c|}
\hline Variable & Unit & Simple cycle (SC) & Parallel cycle (PC) \\
\hline Pinch point temperature difference in the evaporators and condensers & $\left({ }^{\circ} \mathrm{C}\right)$ & $\Delta T_{P P, \text { evap } / \text { cond }} \geq 10$ & $\Delta T_{P P, \text { evap } / \text { cond }} \geq 10$ \\
\hline Superheating level in the ORC exhaust and EGR circuits & $\left({ }^{\circ} \mathrm{C}\right)$ & $\Delta T_{\text {sh,exh } / E G R} \leq 100$ & $\Delta T_{\text {sh }, e x h / E G R} \leq 100$ \\
\hline Evaporation pressure & (bar) & $\begin{array}{l}p_{\text {evap }} \leq 30 \\
\left(\text { or } 0.9 \cdot p_{c} \text { ) }\right.\end{array}$ & $\begin{array}{l}p_{\text {evap }} \leq 30 \\
\left(\text { or } 0.9 \cdot p_{c} \text { ) }\right.\end{array}$ \\
\hline Condensing pressure & (bar) & $p_{\text {cond }} \geq 1.2$ & $p_{\text {cond }} \geq 1.2$ \\
\hline Evaporation temperature & $\left({ }^{\circ} \mathrm{C}\right)$ & $T_{\text {evap }} \geq 50$ & $T_{\text {evap }} \geq 50$ \\
\hline Condensing temperature & $\left({ }^{\circ} \mathrm{C}\right)$ & $T_{\text {cond }} \geq 50$ & $T_{\text {cond }} \geq 50$ \\
\hline Exhaust gas temperature at evaporator outlet & $\left({ }^{\circ} \mathrm{C}\right)$ & $T_{\text {exh }, \text { OUT }} \geq 90$ & $T_{\text {exh }, \text { OUT }} \geq 90$ \\
\hline EGR gas temperature at EGR cooler outlet & $\left({ }^{\circ} \mathrm{C}\right)$ & - & $T_{E G R, O U T}=145$ \\
\hline Vapour quality at expansion outlet & $(-)$ & $x_{E, \text { OUT }} \geq 0.9$ & $x_{E, \text { OUT }} \geq 0.9$ \\
\hline Cooling fluid temperature at condenser outlet & $\left({ }^{\circ} \mathrm{C}\right)$ & $T_{c f, \text { cond, OUT }} \leq 125$ & $T_{c f, \text { cond }, \text { OUT }} \leq 125$ \\
\hline Maximum working fluid temperature (expander inlet) & $\left({ }^{\circ} \mathrm{C}\right)$ & $T_{w f, \exp , I N} \leq T_{c}$ & $T_{w f, \exp , I N} \leq T_{c}$ \\
\hline Cooling fluid mass flow & $\left(\mathrm{kg} \mathrm{s}^{-1}\right)$ & $\dot{m}_{c f} \leq 5$ & $\dot{m}_{c f} \leq 5$ \\
\hline
\end{tabular}

- the coolant temperature at the condenser outlet has been limited to $125^{\circ} \mathrm{C}$ to avoid the cooling mixture to boil. In the IC2 heat sink layout, the coolant mass flow has been imposed lower than $5 \mathrm{~kg} / \mathrm{s}$ to keep the design similar to the main engine cooling circuit;

- the vapour quality at the expander outlet has been imposed to be higher than 0.9 in order to avoid liquid droplets formation and possible damaging problems, especially when using turbo-expanders;

As last step, as objective function, it has been chosen to maximize the BSFCimpr parameter (improvement of BSFC in comparison to the baseline engine without ORC), in order to obtain the best brake specific fuel consumption improvement when recovering heat from the engine with the ORC system.

The optimization process has been carried out using EES Optimization Toolbox, and the procedure developed in two steps:

(1) A genetic algorithm (GA) [21] is used to obtain a first global best solution, exploiting the characteristics of the GA of being robust to find a global optimum, but slow and not very accurate. This will guarantee to be close to the global optimal point;

(2) A Nelder-Mead simplex algorithm [22] is used as second step, starting from the GA solution, to find a more accurate best BSFC improvement value, thus refining the search, exploiting the properties of this type of algorithm of being more accurate and fast converging to the solution, but being less robust in finding a global solution;

Once obtained the best solutions for all the examined cases, the heat sink analysis has been carried out on the most promising configurations. The results of the overall procedure are reported in the next section.

\section{Results}

The results of the optimization are proposed in this section, divided between simple cycle (SC) and parallel cycle (PC) ORC layouts, reporting both the heat sink configurations: IC1 (higher-temperature engine cooling circuit) and IC2 (lower-temperature ORC-only cooling circuit).

\section{ORC performance optimization}

In the next sections, the results regarding the ORC simulations for the two different cycle architectures are proposed.

\section{Simple cycle (SC)—exhaust gas heat recovery}

For the simple cycle (SC) layout, the working fluids giving the best BSFC improvement (Table 9) are water-steam for indirect condensation 1 (IC1) heat sink configuration (6.4\%) and methanol for indirect condensation 2 (IC2) configuration (7.7\%). The net power generated is almost in all fluids cases higher when IC2 heat sink is used, due to the lower condensing temperature and higher pressure ratio available through the expander (e.g. $+46 \%$ for methanol from IC1 to IC2 configurations).

The $\sum$ UiAHX, $i$ index gives an idea of the dimensions of the heat exchangers and thus is also a global indicator of the cost of the heat transfer equipment. For example, in case of R-245fa, R-141b and R-123, the power generated is low compared to other fluids examined, and the heat transfer index is proportionally high, thus leading to bulky heat transfer equipment in comparison to the net power obtained. The same problem can be faced in case of methanol: BSFC improvement is high (7.7\% in IC2) but $\sum U i A H X, i$ reveals the need of bulky heat exchangers to 
Table 9 Simple cycle (SC) BSFC improvement (\%) for IC1 and IC2 heat sink configurations

\begin{tabular}{llll}
\hline Simple Cycle (SC) & & & \\
\hline IC1 & & IC2 & 7.7 \\
\hline Water-steam & 6.4 & Methanol & 7.6 \\
Toluene & 6.3 & Acetone & 7.1 \\
Ethanol & 5.1 & Ethanol & 7.0 \\
Acetone & 4.9 & Cyclopentane & 6.7 \\
Methanol & 4.8 & Water-steam & 6.3 \\
Cyclopentane & 4.6 & R-141b & 6.3 \\
R-141b & 3.7 & Toluene & 5.7 \\
R-123 & 3.1 & R-123 & 4.4 \\
MDM & 2.8 & R-245fa & 2.8 \\
R-245fa & 1.7 & MDM & \\
\hline
\end{tabular}

achieve this performance, compared to other fluids. Watersteam reveals a good compromise between ORC net power generated and heat transfer equipment dimensions, especially in IC2 configuration (IC1 shows quite high heat exchangers $U A$ ), and has no flammability and health issues; however, it can lead to freezing problems in particularly cold weather conditions due to the high melting point. Toluene, ethanol, acetone, methanol and cyclopentane, even if with good BSFC improvement potential, still present flammability issues, and a mixture with other fluids, capable to mitigate the problem (e.g. water), could be considered in future studies, especially in case of direct evaporation configurations, in which possible fluid leakage could lead to ignition problems. MDM, even if leading to less bulky equipment and mass flow needs, leads also to low BSFC improvement (2.8\% in both IC configurations). MDM seems to be more suitable in case of medium- to low-temperature heat recovery and the condensing temperature (at 1.2 bar condensing pressure) is also very high, thus leading to decreased pressure ratio available through the expander and decreased net power produced. Some of the considerations proposed above are related to the histograms reported in Fig. 6.

\section{Parallel cycle (PC)—exhaust gas and EGR heat recovery}

For the parallel cycle (PC) ORC layout, the working fluids giving the best BSFC improvement (Table 10) are toluene for indirect condensation 1 (IC1) heat sink configuration (9.2\%) and methanol for indirect condensation 2 (IC2) configuration $(10.6 \%)$. Also in this case, there is a sensible increase in the net power generated from IC1 to IC2 (e.g. $+57 \%$ in case of methanol).

Generally, the same conclusions of SC cases can be drawn for the PC layout cases, with the difference that the PC layout leads to increased heat recovery, increased net power output and thus increased BSFC improvement potential compared to SC. Even though the PC layout leads to an increase in heat rejection compared to the SC layout, it also allows the ORC to recover the EGR heat to produce additional useful power. If not recovered, this heat would have impact on the overall vehicle thermal management, since it would need to be rejected, in the EGR cooler, to the cooling system and then to the ambient through the cooling package, requiring additional fan parasitic power consumption. Moreover, water-steam, despite his problems of freezing in case of low ambient temperatures, shows a very good potential (high BSFC improvement and low heat rejection compared to other fluids, due to higher cycle thermal efficiency). However, in case of IC1 heat sink layout, the heat exchangers result in being quite bulky, as reported in Fig. 7.

From the analysis carried out with ten different working fluids, it has been confirmed that R-245fa, R-141b, R-123 and MDM are not suitable for medium- to high-temperature heat sources such as exhaust gas and EGR. Toluene,

\section{(a) ORC Net Power}

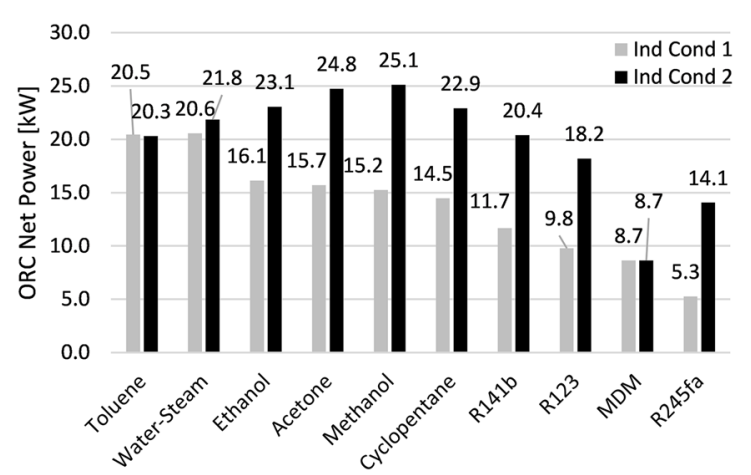

(b) UA

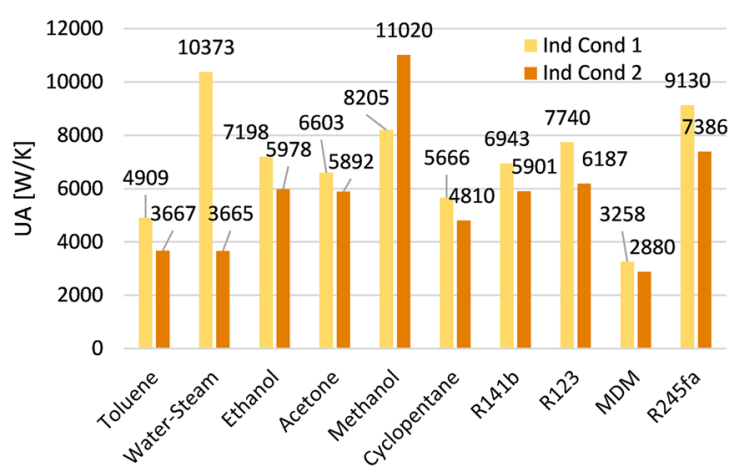

Fig. 6 a ORC net power output and b heat exchangers UA coefficient for Simple Cycle (SC) 
Table 10 Parallel cycle (PC) BSFC improvement (\%) for IC1 and IC2 heat sink configurations

\begin{tabular}{lllr}
\hline Parallel Cycle (SC) & & & \\
\hline IC1 & & IC2 & 10.6 \\
\hline Toluene & 9.2 & Methanol & 10.2 \\
Water-steam & 9.1 & Acetone & 10.0 \\
Ethanol & 6.8 & Water-steam & 9.9 \\
Acetone & 6.6 & Cyclopentane & 9.9 \\
Cyclopentane & 6.3 & Ethanol & 9.2 \\
Methanol & 5.9 & Toluene & 8.7 \\
R-141b & 4.9 & R-141b & 7.7 \\
MDM & 4.2 & R-123 & 6.1 \\
R-123 & 4.1 & R-245fa & 4.2 \\
R-245fa & 1.9 & MDM & \\
\hline
\end{tabular}

ethanol, methanol, acetone, cyclopentane and water-steam have been considered possible choices for a preliminary ORC concept, based on the prescribed boundary conditions, and have been evaluated in the heat sink study reported in the next section.

\section{Heat sink study}

The heat rejected by the ORC system at the condenser must be transferred to the cooling loops and then to the ambient through the radiator (or through the two separated radiators in the case of IC2 heat sink configuration).

In Table 11, the heat rejected by the ORC systems in the various considered configurations is reported.

The data reported in Table 11 show a higher heat rejection in the PC layout (+40-60\% if compared to SC), mostly due to the heat recovered in the EGR and introduced in the cycle. However, the EGR heat, if not recovered, should be anyway rejected to the ambient, thus being an additional thermal load for the vehicle thermal management system.

The EES code developed has been used in order to assess the heat rejection capabilities and dimensions needed for the combined engine-ORC radiator (IC1 configuration) or for the ORC rooftop radiator (IC2) reported in Fig. 5. In case of IC2 configuration, an additional fan is required to cool the ORC radiator, but still the conventional fan is used to cool the engine cooling package. In case of SC layout, the engine radiator must reject both engine and EGR heat, while in case of PC layout, only the engine heat, since the EGR heat is recovered by the ORC. The fan consumption of the baseline engine radiator must anyway be considered in the power balance analysis.

In case of IC1 configuration, the power balance can be reported as:

$\Delta P=P_{\text {ORC }, \text { net }}-P_{\text {eng } / \text { ORC }, \text { fan }}$

With $P_{\text {eng/ORC,fan }}$ the power consumption of the fan of the combined engine-ORC radiator.

In the case of the IC2 configuration, in addition to the separate rooftop ORC fan consumption $\left(P_{\text {ORC fan }}\right)$ also the fan consumption of the baseline engine radiator has to be considered $\left(P_{\text {eng.fan }}\right.$, with or without EGR heat rejection depending on the ORC layout):

$\Delta P=P_{\text {ORC,net }}-P_{\text {ORC,fan }}-P_{\text {eng.fan }}$

These power balances must be maximized in order to obtain the best benefit, considering also that increasing the radiator dimensions usually decreases the fan power consumption, but increases space and design issues.

In this study, however, no optimization algorithm has been used to size the radiator, but the main dimensions, width (W), height (H) and depth (D), have been changed and the fan power consumption estimated, always considering radiator shape and size having in mind an actual implementation, especially when using the configuration

\section{(a) ORC Net Power}

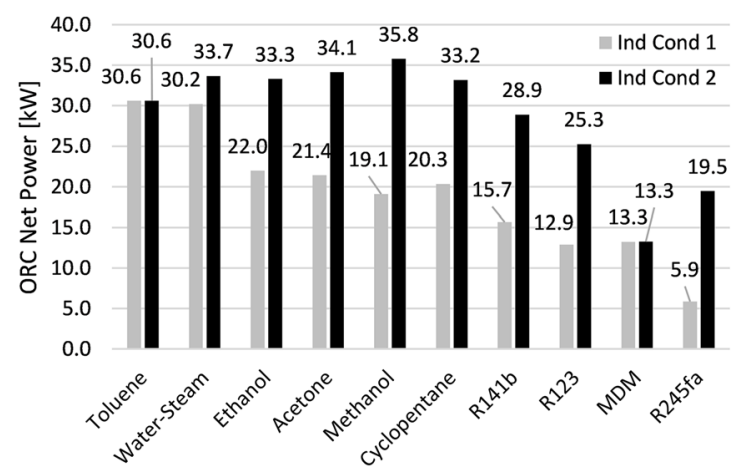

\section{(b) UA}

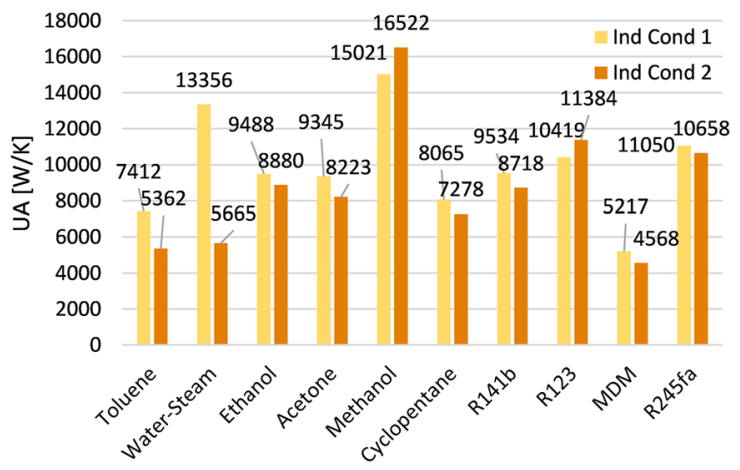

Fig. 7 a ORC net power output and $\mathbf{b}$ heat exchangers UA coefficient for parallel cycle (PC) 
Table 11 ORC system heat rejection for the four cases evaluated and the working fluids considered

\begin{tabular}{lllll}
\hline$\dot{Q}_{\text {ORC,OUT }}(\mathrm{kW})$ & & & & \\
\hline Fluids & SC-IC1 & SC-IC2 & PC-IC1 & PC-IC2 \\
\hline Toluene & 128.2 & 128.4 & 191.5 & 191.5 \\
Water-steam & 107.9 & 107.8 & 171.8 & 171.1 \\
Ethanol & 135 & 138.9 & 200.7 & 202.2 \\
Acetone & 135.4 & 137.5 & 201.4 & 201.9 \\
Methanol & 136 & 137.2 & 203.6 & 200 \\
Cyclopentane & 137 & 138.2 & 203.3 & 202.8 \\
R141b & 139.9 & 142 & 207.9 & 207.8 \\
R123 & 142 & 142.2 & 211 & 211.9 \\
MDM & 125.4 & 125.4 & 192.1 & 192.1 \\
R245fa & 147.4 & 150 & 205.1 & 218.7 \\
\hline
\end{tabular}

IC1 with a combined engine-ORC radiator, which must still fit in the engine underhood compartment.

In particular, for IC1 configuration, a maximum of $10-30 \mathrm{~cm}$ increase in height $(\mathrm{H})$ and width $(\mathrm{W})$ and $4-5 \mathrm{~cm}$ in depth (D) have been considered in this study.

For configuration IC2 (rooftop installation), an increase in maximum $50 \mathrm{~cm}$ in height and width, and $7 \mathrm{~cm}$ in depth has been tolerated, due to less stringent space constraints.

The new radiator dimensions have then been compared to the engine baseline radiator, with frontal area, $A_{f, r a d}$, of $1 \mathrm{~m}^{2}$, and the core volume, $V_{\text {rad }}$, of $0.08 \mathrm{~m}^{3}$.

\section{Simple cycle-indirect condensation 1 (SC-IC1)}

The best trade-off between radiator dimensions and fan parasitic consumption is obtained with water-steam as working fluid, $40 \%$ percentage increase (calculated as difference between new and baseline radiator dimensions) in radiator frontal area and $90 \%$ in radiator volume compared to the baseline component, with an estimated fan consumption of around $13 \mathrm{~kW}$, reduced in comparison with the engine-only radiator due to the increased dimensions. Toluene can lead also to a good compromise (40\% frontal area and $110 \%$ volume increase), but with increased fan consumption $(17.3 \mathrm{~kW})$ when considering almost the same increase in component dimensions. Toluene is also not as safe as water, due to flammability problems.

For the other fluids considered, the compromise cannot be considered as good. Indeed, in these cases, it is necessary to further increase the radiator dimensions in order to achieve positive trade-off values.

The IC1 heat sink configuration is the most compact solution, when trying to fit the ORC thermal management components in the vehicle-cooling package, as well as the most compact in terms of ORC components dimensions.
In every case evaluated, it is not possible to achieve the required heat rejection performance using the same baseline engine radiator dimensions, because of the additional exhaust gas recovered heat which must then also be rejected at the condensing side.

\section{Parallel cycle-indirect condensation 1 (PC-IC1)}

This configuration is beneficial regarding both ORC performance and thermal management. Indeed, EGR heat is recovered by the ORC system, thus producing net power from the heat that otherwise should be rejected in the engine cooling circuit, and then to the ambient through the radiator.

Also in this case, the best trade-off between radiator dimensions and fan parasitic power consumption can be obtained with water-steam. With the same percentage increase in frontal area (40\%) and volume $(90 \%)$ of SC case, the fan consumption drops from 13 to $6.2 \mathrm{~kW}$, while the net ORC power generated increases from 20.6 to $30.2 \mathrm{~kW}$. In this case, it would be also possible to decrease the combined engine-ORC radiator dimensions still keeping a good compromise between dimensions and parasitic fan consumption. Also in this case, the second best choice is Toluene $(30.6 \mathrm{~kW}$ ORC net power and $8.2 \mathrm{~kW}$ fan consumption), while the other fluid still give acceptable compromises compared to the SC-IC 1 case.

Generally, even if adding an additional heat exchanger (EGR boiler) is detrimental regarding packaging, cost, weight and system complexity issues, the compromise between performance and thermal management is better than in the case of the SC layout, when using IC1 heat sink configuration, or compared to the baseline configuration without ORC system.

\section{Simple cycle-indirect condensation 2 (SC-IC2)}

In case of using the lower-temperature cooling circuit, even though the condensing temperature can be decreased, the temperature difference between the coolant and the ambient air is also smaller, thus leading to the need of drastically increasing the radiator dimensions in order to keep a good compromise with fan parasitic consumption (100\% increase in frontal area and $275 \%$ in volume). Furthermore, the positive effect of using the ORC, is almost completely overcome by the need to reject a high amount of heat to the ambient when recovering exhaust gas but not EGR. For this reason, SC-IC2 configuration gives basically no benefits, being the $\Delta P$ parameter basically always negative when considering even consistent radiator dimensions' increase.

\section{Parallel cycle-indirect condensation 2 (PC-IC2)}

In this case, considering the same frontal area and volume dimensions increase compared to engine baseline radiator 
Table 12 ORC-heat sink study best configurations

\begin{tabular}{lllllll}
\hline Fluid & Config. & $A_{\text {f,rad,incr }}(\%)$ & $V_{\text {rad,incr }}(\%)$ & $P_{\text {fan }}(\mathrm{kW})$ & $P_{\text {ORC,net }}(\mathrm{kW})$ & $\Delta P(\mathrm{~kW})$ \\
\hline Water-steam & PC-IC1 & 40 & 90 & 6.2 & 30.2 & 24.0 \\
Toluene & PC-IC1 & 40 & 90 & 8.2 & 30.6 & 22.4 \\
Ethanol & PC-IC2 & 100 & 275 & 15.1 & 33.3 & 18.2 \\
Acetone & PC-IC1 & 40 & 90 & 9.3 & 21.4 & 12.1 \\
Cyclopentane & PC-IC1 & 40 & 90 & 9.7 & 20.3 & 10.6 \\
Methanol & PC-IC1 & 40 & 90 & 9.7 & 19.1 & 9.4 \\
\hline
\end{tabular}

used in SC-IC2 configuration, the best trade-off is given by ethanol (33.3 kW ORC net power generation and $15.1 \mathrm{~kW}$ fan consumption). This is because the coolant mass flow required for ethanol case is lower than for water-steam or other fluids, while the coolant temperature at the radiator inlet is higher, thus leading to a higher $\Delta T$ with the cooling ambient air and smaller radiator dimensions-fan parasitic consumption compromise. Water-steam still gives a good compromise, but with higher fan consumption $(19.4 \mathrm{~kW})$, even if with similar ORC net produced power $(33.7 \mathrm{~kW})$. Other fluids lead to not comparable benefits.

Also in this configuration, increasing the radiator dimensions is beneficial in order to reduce fan power consumption. This could be compatible with a rooftop installation; however, weight and cabin resistance issues must be considered, as well as layout complexity.

\section{Overall results}

The first six best configurations, and relative power balance and radiator dimensions' increase, obtained after the heat sink study have been reported in Table 12 .

From a comparison of the results, it emerges how the parallel cycle (PC) ORC layout is always the best choice compared to the simple cycle (SC) regarding ORC and heat rejection performance.

In particular, for IC1 heat sink configuration (engine cooling circuit), the recovery of EGR heat is beneficial also for thermal management, since the heat, that otherwise has to be rejected to the engine cooling circuit and then to the ambient through the radiator, is used to produce additional net power in the ORC. EGR recovery allows also smaller radiator dimensions and a better compromise with fan consumption, due to the fact that part of the EGR recovered heat is converted into useful power in the ORC, and a lower amount of heat is then rejected to the coolant, thus reducing the impact on the vehicle thermal management system.

IC2 heat sink configuration (LT cooling circuit) is not very beneficial. This is mainly due to the fact that a lower coolant temperature leads to a lower temperature difference between coolant and cooling air in the radiator, and thus higher heat transfer area requirements. This configuration could be used when lower ambient temperature conditions are expected and when ethanol is used.

An improved trade-off could be obtained when using Toluene (dry fluid) with a internal recuperator configuration, thus allowing the same ORC net power output, but with a decreased recovered heat amount, also allowing a lower amount of heat to be rejected in the cooling circuit after the ORC. However, this would require an additional heat exchanger, thus increasing system complexity, costs and packaging design issues.

\section{Conclusions}

An ORC process simulation model has been implemented in order to find the optimal combination of working fluid, ORC architecture layout and heat sink configuration, to increase the fuel efficiency of an agricultural tractor powered by a two-stage turbocharged heavy-duty diesel engine.

The results of the study show how the choice of the best solution, especially in vehicle applications, is always a trade-off between several considerations: ORC performance, heat rejections capabilities and vehicle thermal management, fluids properties (safety, flammability, availability and environmental impact), packaging and weight constraints, components choice and performance, engine and ambient boundary conditions.

In the cases analysed, even if methanol or acetone in PC-IC 2 configuration, give the best BSFC improvement (10.6 and $10.2 \%$, respectively), fan consumption and radiator dimensions are higher than in the case of watersteam, toluene or ethanol, leading to an overall reduced benefit when considering engine cooling needs. Watersteam, even with possible freezing problems, can be a valuable choice regarding performance and thermal management. Water has a very high potential for waste heat recovery in the temperature range considered in this application $\left(500-600{ }^{\circ} \mathrm{C}\right.$, exhaust gas and EGR), is safe in operations, readily available, non-toxic, chemically stable and environmentally friendly. Toluene and ethanol, 
even if with more safety and flammability concerns, present less freezing issues and still good thermodynamic performance.

Recovering EGR heat is beneficial both regarding ORC performance and vehicle thermal management because, particularly with heat sink IC1 configuration, it allows to reduce combined engine-ORC radiator dimensions and fan power consumption and, at the same time, to improve the overall powertrain performance at the expense of a more complicated architecture, due to the ORC components installation. However, the engine cooling layout remains similar to the baseline one.

The IC2 configuration is not very beneficial. Indeed, in case of ethanol and PC layout, the overall powertrain will benefit from an increased power output but encompassing a bulkier and more complicated cooling system, and an increased fan parasitic consumption.

Regarding the thermal management side, a more accurate 3D CFD analysis can be used in order to assess radiator performance and heat rejection under more realistic operational conditions. Furthermore, heat and pressure losses, combined engine back-pressure effects and a cost analysis and feasibility are not assessed in this study, but must be considered for future research and development activities.

Acknowledgements The work reported above has been presented at the 29th International Conference on Efficiency, Cost, Optimisation, Simulation and Environmental Impact of Energy Systems (ECOS 2016) in Portorož, Slovenia and chosen for peer review publication.

Funding The research leading to these results has received funding from the People Programme (Marie Curie Actions) of the European Union's Seventh Framework Programme FP7/2007-2013/ under REA grant agreement n 607214 .

Open Access This article is distributed under the terms of the Creative Commons Attribution 4.0 International License (http://crea tivecommons.org/licenses/by/4.0/), which permits unrestricted use, distribution, and reproduction in any medium, provided you give appropriate credit to the original author(s) and the source, provide a link to the Creative Commons license, and indicate if changes were made.

\section{References}

1. Sprouse, C., Depcik, C.: Review of organic Rankine cycles for internal combustion engine exhaust waste heat recovery. Appl. Therm. Eng. 51, 711-722 (2013)

2. Wang, T., Zhang, Y., Peng, Z., Shu, G.: A review of researches on thermal exhaust heat recovery with Rankine cycle. Renew. Sustain. Energy Rev. 15, 2862-2871 (2011)

3. Patel, P.S., Doyle, E.F.: Compounding the truck diesel engine with an organic Rankine-cycle system. SAE Technical Paper 760343. Society of Automotive Engineers, Michigan (1976). doi: $10.4271 / 760343$

4. DiBella, F.A., DiNanno, L.R., Koplow, M.D.: Laboratory and On-highway testing of diesel organic rankine compound longhaul vehicle engine. SAE. Tech. Pap. Ser. 29, 38 (1983)
5. Nelson, C.: Exhaust energy recovery. In Proceedings of Diesel Engine-Efficiency and Emissions Research (DEER) Conference, Dearborn, MI, 4-7 Aug 2008

6. Aneja, R., Singh, S., Sisken, K., Dold, R., Oelschlegel, H.: Exhaust heat driven rankine cycle for a heavy duty diesel engine (DAIMLER Presentation). DEER 2011, Detroit (2011). Available at: https://energy.gov/sites/prod/files/2014/03/f8/deer11_singh. pdf

7. Seher, D., Lengenfelder, T., Gerhardt, J., Eisenmenger, N., Hackner, M., Krinn, I.: Waste Heat Recovery for Commercial Vehicles with a Rankine Process. 21 st Aachen Colloq. Automob. Engine Technol. 2012. (2012)

8. Diesel Systems-Waste Heat Recovery System for commercial vehicles-Brochure, Robert BOSCH GmbH, http://products. bosch-mobility-solutions.com/media/ubk_europe/db_application/ downloads/pdf/antrieb/en_3/DS-Datenbl_P1A8_WHR_EN_low. pdf (2014)

9. Furukawa, T., Nakamura, M., Machida, K., Shimokawa, K.: A study of the rankine cycle generating system for heavy duty HV Trucks. In: SAE 2014 World COngress \& Exhibition., Detroit, Michigan, USA (2014)

10. Howell, T., Gibble, J., Tun, C.: Development of an ORC system to improve HD truck fuel efficiency-Ricardo. In: Deer Conference. pp. 1-21 (2011)

11. Maybin, B., Hanna, A., Rouaud, C., Porteous, S., Baxter, J., Douglas, R., Nolan, C., Seaman, R.: The energy and thermal management of a hybrid double deck bus. In: 23rd Aachen Colloquium Automobile and Engine Technology (2014)

12. Nolan, C., Douglas, R., O'Shaughnessy, R., Rouaud, C., Foley, A.: Improving fuel economy application of the organic rankine cycle on a hybrid bus. Ingegneria dell'Autoveicolo 67(5), 32 (2014)

13. Nolan, C., O'Shaughnessy, R., Douglas, R., Rouaud, C.: Waste heat recovery utilising engine coolant on a hybrid bus. In: Vehicle Thermal Management Systems Conference Proceedings., Coventry, UK (2013)

14. Briggs, I., McCullough, G., Spence, S., Douglas, R., O'Shaughnessy, R., Hanna, A., Rouaud, C., Seaman, R.: Waste Heat Recovery on a Diesel-Electric Hybrid Bus Using a Turbogenerator. In: SAE 2012 Commercial Vehicle Engineering Congress (2012)

15. Nolan, C., O'Shaughnessy, R., Douglas, R., Rouaud, C., Hanna, A., Seaman, R.: Waste heat recovery to improve fuel economy on a hybrid bus. In: Proceedings of MTZ heavy duty on and off highway engines conference, Ludwigsburg, Germany (2013)

16. Katsanos, C., Hountalas, D.T., Zannis, T.C., Yfantis, E.A.: Potentiality for Optimizing Operational Performance and Thermal Management of Diesel Truck Engine Rankine Cycle by Recovering Heat in EGR Cooler. In: SAE 2010 World Congress \& Exhibition., Detroit, Michigan, USA (2010)

17. Hountalas, D.T., Mavropoulos, G.C., Katsanos, C., Knecht, W.: Improvement of bottoming cycle efficiency and heat rejection for HD truck applications by utilization of EGR and CAC heat. Energy Convers. Manag. 53, 19-32 (2012)

18. Katsanos, C., Hountalas, D.T., Pariotis, E.G.: Thermodynamic analysis of a Rankine cycle applied on a diesel truck engine using steam and organic medium. Energy Convers. Manag. 60, 68-76 (2012)

19. Latz, G., Erlandsson, O., Skåre, T., Contet, A.: Water-based Rankine-cycle waste heat recovery systems for engines: challenges and opportunities. ASME ORC 2015, 1-10 (2015)

20. Klein, S.A.: EES (Engineering Equation Solver)—Professional Version V9.710-3D. F-Chart Software, http://www.fchart.com/

21. F-Chart Software: EES-Genetic Method, http://www.fchart. com/ees/eeshelp/genetic_method.htm

22. F-Chart Software: EES-Nelder Mead Simplex Method, http:// www.fchart.com/ees/eeshelp/nelder_mead_simplex_method.htm 
23. US EPA: Nonregulatory Nonroad Duty Cycles, http://www.epa. gov/otaq/regs/nonroad/nrcycles.htm

24. Qiu, T., Li, X., Liang, H., Liu, X., Lei, Y.: A method for estimating the temperature downstream of the SCR (selective catalytic reduction) catalyst in diesel engines. Energy. 68, 311-317 (2014)

25. Branchini, L., De Pascale, A., Peretto, A.: Systematic comparison of ORC configurations by means of comprehensive performance indexes. Appl. Therm. Eng. 61, 129-140 (2013)

26. Incropera, F.P., DeWitt, D.P., Bergman, T.L., Lavine, A.: Fundamentals of heat and mass transfer. Wiley, New Jersey (2007)

27. Cowell, T.: The Performance of Engine Cooling Heat Exchangers (Internal Ricardo Resources) (2008)

28. F-Chart Software: EES help-Heat Transfer Library-Internal Flow_DuctFlow, http://fchart.com/ees/heat_transfer_library/ internal_flow/hs1110.htm

29. Nellis, G.F., Klein, S.A.: Heat Transfer. Cambridge University Press, Cambridge (2009)
30. Multi-Wing: Optimiser fan selection software, v.10. Available at: http://www.multi-wing.com/Downloads/Optimiser

31. Ružić, D., Časnji, F.: Agricultural tractor cab characteristics relevant for microclimatic conditions. J. Appl. Eng. Sci. 9, 323-330 (2011)

32. NFPA (National Fire Protection Association): NFPA 704: Standard system for the identification of the hazards of materials for emergency response. Available at: http://www.nfpa.org

33. United Nations (UN). Kyoto protocol to the United Nations framework convention on climate change (1998). Available at: https://unfccc.int/resource/docs/convkp/kpeng.pdf

34. Lemmon, E.W., Huber, M.L., McLinden, M.O.: NIST standard reference database 23: reference fluid thermodynamic and transport properties-REFPROP. Version 9.1, National Institute of Standards and Technology, Standard Reference Data Program, Gaithersburg (2013) 